American Journal of Environmental Sciences 5 (1): 87-93, 2009

ISSN $1553-345 \mathrm{X}$

(C) 2009 Science Publications

\title{
An Analysis of Urban Land Development Using Multi-Criteria Decision Model and Geographical Information System (A Case Study of Babolsar City)
}

\author{
${ }^{1}$ Sedigheh Lotfi, ${ }^{2}$ Kiomarth Habibi and ${ }^{3}$ Mohammad Javad Koohsari \\ ${ }^{1}$ Department of Urban Planning, Faculty of Humanities and Socil Sciences, \\ University of Mazandaran, Babolsar/ Iran \\ ${ }^{2}$ Department of Urban and Regional Planning, Faculty of Art and Architecture, University \\ of Kurdistan, Sannandaj/ Iran \\ ${ }^{3}$ Department of Urban and Regional Planning, Faculty of Fine Arts, University of Tehran, Tehran/ Iran
}

\begin{abstract}
Problem Statement: The unplanned physical expansion of cities has been one of the most important problems of urban management in developing countries. Iran, like other developing world has experienced a high level of urbanization growth which transformed the physical fabric of urban areas. North of Iran is one of most rapid growing region of the country where the moderate climate and a tourism based economy encouraged many developers to investigate in housing sector. So, the primary outcome of such process was the out-growth of the city boundaries in the region. Approach: This research attempted to present an appropriate model for urban physical development. The study used different parameters such as environmental and socio-economic factors to provide a good understanding of the city behavior in its geographical setting. Through applying the Multi-Criteria Decision Model (MCDA) and GIS, the most appropriate area introduced for near future development. Results: The results revealed that the integrated GIS and MCDA model has many potentials which allow the planner or user investigate the final decision for site selection for future urban physical development. Conclusion: Since the city is located in a fertile agricultural area where the general policy of the local government is to save the lands for strategic crops like rice, to select the right site for city development is quiet significant.
\end{abstract}

Key words: Physical expansion, land use planning, Land compatibility, urban planning, Iran

\section{INTRODUCTION}

The physical expansion of the cities is a dynamic process which changes the physical space of the city in a vertical or horizontal direction. If this process takes place in an unplanned manner, the physical balance of urban areas would be challenged and soon urban system is not able to function properly. Many of small and intermediate cities of the country have developed on the margins of their limits where the urban incompatible land uses created many problems ${ }^{[1]}$.

The unplanned physical growth is one the most challenging problems in the developing countries which impose many socio-economic and environmental constrain. So, the physical growth of cities should be guide and control by considering the different parameters which influence the city expansion. Managing a city needs a large amount of data and information which the traditional methods are not able to do deal with them. The complexity of the urban land uses and their functions could be managed and perceived only by using a powerful tool such as GIS. One of the models which can decrease the cost and has a high potential for spatial decision making is Multicriteria Decision Model Analysis (MCDA).

Babolsar town is one of the northern cities of the Mazandaran province in the southern coast of the Caspian Sea. The town is located in the middle of agricultural fertile lands. Iran as arid and semi arid region has a limited area of cultivable land which is mainly scratched in the north. The central policy of the Iranian government is to save agricultural land for the cultivation of rice as strategic crop. But the unprecedented urban physical growth has threatened the most of the periphery areas of the city in the region. So this study tries by using an efficient model for appropriate urban development in the area.

Corresponding Author: Dr. Sedigheh Lotfi, Department of Urban Planning, Faculty of Humanities and Social Sciences, University of Mazandaran, Babolsar, Iran 


\section{MATERIALS AND METHODS}

Multi model decision making refers to a process of valuing different alternatives which are investigated by several criteria. The multi criteria decision making could be divided into the two broad classes: multiattribute and multi-objective decision making.

If the investigated case is a confined set of alternatives for selecting of the best one according to the weight of each alternative characteristic, this case would be a Multi-attribute decision making. The multiobjective decision making selects the best alternatives on the base of much incompatible objectives ${ }^{[2]}$. The multi-objective models are used for design while multi objective models are applied for selecting the best alternative $\mathrm{e}^{[3]}$.

The Multi Criteria Decision Making (MCDM) is a set of techniques (e.g., sum of weights or conversion analysis) which is able to weight and score a range of criteria and then the scores are ranked by the expertise and other related interested groups ${ }^{[3]}$.

Statistics reveal that more than 80 percent of information relates to space and situation in the daily life of human being ${ }^{[4]}$.

The MCDA techniques are spatial in much degree. In fact, criteria are different among the number of decision in space ${ }^{[5]}$ However, despite the potential of MCDA model for integration to deal with spatial units problems, it gained attention only in a certain period of times in some practical researches and managerial limits ${ }^{[6]}$ Urban planners used the strategy of MCDA integration for dealing with spatial issues from $1990 \mathrm{~s}^{[7]}$ A city system can not be studied only by considering the simple concepts like land use or traffic. Now planners need to develop and deepen their understanding about a city system by analyzing a various socio-economic and political indicators. The issues which need to be dealt at same times create a condition which many alternatives should be tested and integrated to improve ${ }^{[8]}$.

So, using an analyzing tool for the huge volume of data is quite necessary to optimize the MCDA models. GIS can provide an appropriate context for data analysis which is useful tool integration with into MCD methods. Therefore, using MCDA and GIS has a high efficiency for solving spatial problems in urbanism; as in one hand this method could provide an organized framework for consider the effective criteria on spatial issues and weighting them through multi criteria decision strategy and in the other GIS can analysis the large data to determine the most appropriate decisions. Carver and Openshaw stated four main benefits for using integrated MCDA and GIS:
- This method has the ability to perform the complex analysis of many different criteria.

- This model uses factor weighting to integrate the analysis for value judgments.

- It creates a systematic framework of analysis.

- It has all of the advantages of the GIS data base ${ }^{[9]}$.

The AHP approach, developed by ${ }^{[10]}$ is one of the more extensively used MCDM methods. The AHP has been applied to a wide variety of decisions and the human judgment process ${ }^{[11]}$. This technique is one of the MCDA methods with many capabilities which is used in different scientific disciplines. The previous researches show that the technique of MCDA which is known AHP, is very suitable for solving complicated issues $^{[12]}$. Obtaining solutions in the AHP is not a statistical procedure, because it can help either a single decision maker or a decision group to solve a MCDM problem ${ }^{[13]}$. One of the most important advantages of AHP relates to its ability to measure quantitative and qualitative characteristics of a decision ${ }^{[14]}$

Applying the AHP procedure involves three basic steps: (1) decomposition, or the hierarchy construction; (2) comparative judgments, or defining and executing data collection to obtain pair wise comparison data on elements of the hierarchical structure; and (3) synthesis of priorities, or constructing an overall priority rating $^{[15]}$.

In first stage, the decision makers need to break down complex multiple criteria decision problems into its component parts of which every possible attributes are arranged into multiple hierarchical levels.

The criteria and subcriteria are not each equally important to the decision at each level of the hierarchy and each alternative rates differently on each criteria. AHP can provide an analytical process that is able to combine and consolidate the evaluations of the alternatives and criteria by either an individual or group involved in the decision-making task ${ }^{[6]}$.

One notes that two elements being compared at a given time greatly reduces the conceptual complexity of an analysis. This simplification involves assumptions that ${ }^{[17,18,10]}$ considered reasonable. Given a pair wise comparison, the analysis involves three tasks: (1) developing a comparison matrix at each level of the hierarchy starting from the second level and working down, (2) computing the relative weights for each element of the hierarchy and (3) estimating the consistency ratio to check the consistency of the judgment ${ }^{[4]}$. the comparisons can be carried out through personal or subjective judgments ${ }^{[13]}$. 
Table 1: 9-point intensity of relative importance scale

\begin{tabular}{|c|c|c|}
\hline \multicolumn{2}{|c|}{$\begin{array}{l}\text { Intensity of definition } \\
\text { importance }\end{array}$} & Explanation \\
\hline 1 & $\begin{array}{l}\text { Equal } \\
\text { Importance }\end{array}$ & $\begin{array}{l}\text { Two activities contribute } \\
\text { equally to the objective }\end{array}$ \\
\hline 3 & $\begin{array}{l}\text { Weak importance } \\
\text { of one over } \\
\text { another }\end{array}$ & $\begin{array}{l}\text { Experience and judgment } \\
\text { slightly favor } \\
\text { one activity over another }\end{array}$ \\
\hline 5 & $\begin{array}{l}\text { Essential or } \\
\text { strong importance }\end{array}$ & $\begin{array}{l}\text { Experience and judgment } \\
\text { strongly favor } \\
\text { one activity over another }\end{array}$ \\
\hline 7 & $\begin{array}{l}\text { Demonstrated } \\
\text { importance }\end{array}$ & $\begin{array}{l}\text { An activity is strongly } \\
\text { favored and its dominance is } \\
\text { demonstrated in practice }\end{array}$ \\
\hline 9 & $\begin{array}{l}\text { Absolute } \\
\text { Importance }\end{array}$ & $\begin{array}{l}\text { The evidence favoring one } \\
\text { activity over another is of the } \\
\text { highest possible order of } \\
\text { affirmation }\end{array}$ \\
\hline $2,4,6,8$ & $\begin{array}{l}\text { Intermediate values } \\
\text { between the two } \\
\text { adjacent judgments }\end{array}$ & when compromise is needed \\
\hline $\begin{array}{l}\text { Reciproc } \\
\text { of above } \\
\text { nonzero }\end{array}$ & $\begin{array}{l}\text { If activity } i \text { has one } \\
\text { of the above nonzero } \\
\text { numbers assigned to } \\
\text { it when compared with } \\
\text { activity } j \text {, then } j \text { has } \\
\text { the reciprocal value. } \\
\text { when compared with } i\end{array}$ & \\
\hline
\end{tabular}

The 9-point scale used in typical analytic hierarchy studies is ranging from 1 (indifference or equal importance) to 9 (extreme preference or absolute importance) Table 1. This pair wise comparison enabled the decision maker to evaluate the contribution of each factor to the objective independently, thereby simplifying the decision making process.

Elements in each level are compared in pairs with respect to their importance to an element in the next higher level. Starting at the top of the hierarchy and working down, the pair wise comparisons at a given level can be reduced to a number of square matrices $\mathrm{A}=\left[\alpha_{\mathrm{ij}}\right]_{\mathrm{n} \times \mathrm{n}}$ as in the following:

$$
\left(\begin{array}{cccc}
a_{11} & a_{12} & \ldots & a_{1 n} \\
a_{21} & a_{22} & \ldots & a_{2 n} \\
\cdot & \cdot & & \cdot \\
a_{1 n} & a_{2 n} & \ldots & a_{n n}
\end{array}\right)
$$

The matrix has reciprocal properties, which are:

$$
a_{j i}=\frac{1}{a_{i j}}
$$

After all pair wise comparison matrices are formed, the vector of weights, $\mathrm{w}=\left[\mathrm{w}_{1}, \mathrm{w}_{2}, \ldots, \mathrm{w}_{\mathrm{n}}\right]$, is computed on the basis of Satty's eigenvector procedure. The computation of the weights involves two steps. First, the pair wise comparison matrix $A=\left[\alpha_{i j}\right]_{n \times n}$ is normalized by Eq. 1 and then the weights are computed by Eq. 2 .

$$
\mathrm{a}_{\mathrm{ij}}{ }^{*}=\frac{\mathrm{a}_{\mathrm{ij}}}{\sum_{\mathrm{i}=1}^{\mathrm{n}} \mathrm{a}_{\mathrm{ij}}}
$$

for all $\mathrm{j}=1,2, \ldots, \mathrm{n}$

$\mathrm{w}_{\mathrm{i}}=\frac{\sum_{\mathrm{j}=1}^{\mathrm{n}} \mathrm{a}_{\mathrm{ij}}{ }^{*}}{\mathrm{n}}$

for all $i=1,2, \ldots, n$

Satty ${ }^{[10]}$ showed that there is a relationship between the vector weights, $\mathrm{W}$ and the pair wise comparison matrix, A, as shown in Eq. 3.

$$
\mathrm{Aw}=\lambda_{\max } \mathrm{w}
$$

The $\lambda_{\max }$ value is an important validating parameter in AHP and is used as a reference index to screen information by calculating the Consistency Ratio (CR) of the estimated vector. To calculate the CR, the Consistency Index (CI) for each matrix of order $n$ can be obtained from Eq. 4.

$$
\mathrm{C} I=\frac{\lambda_{\max }-\mathrm{n}}{\mathrm{n}-1}
$$

Then, CR can be calculated using Eq. 5:

$$
\mathrm{CR}=\frac{\mathrm{CI}}{\mathrm{RI}}
$$

Where RI is the random consistency index obtained from a randomly generated pair wise comparison matrix? Table 2 shows the value of the RI from matrices of order 1 to 10 as suggested by Satty. If $\mathrm{CR}<0.1$, then the comparisons are acceptable. If, however, $C R \geq 0.1$, then the values of the ratio are indicative of inconsistent judgments. In such cases, one should reconsider and revise the original values in the pair wise comparison matrix A.

The AHP was adopted in education, engineering, government, industry, management, manufacturing, personal, political, social and sports ${ }^{[19]}$. The wide 
Table 2: Random inconsistency indices (ri) for $\mathrm{n}=10$
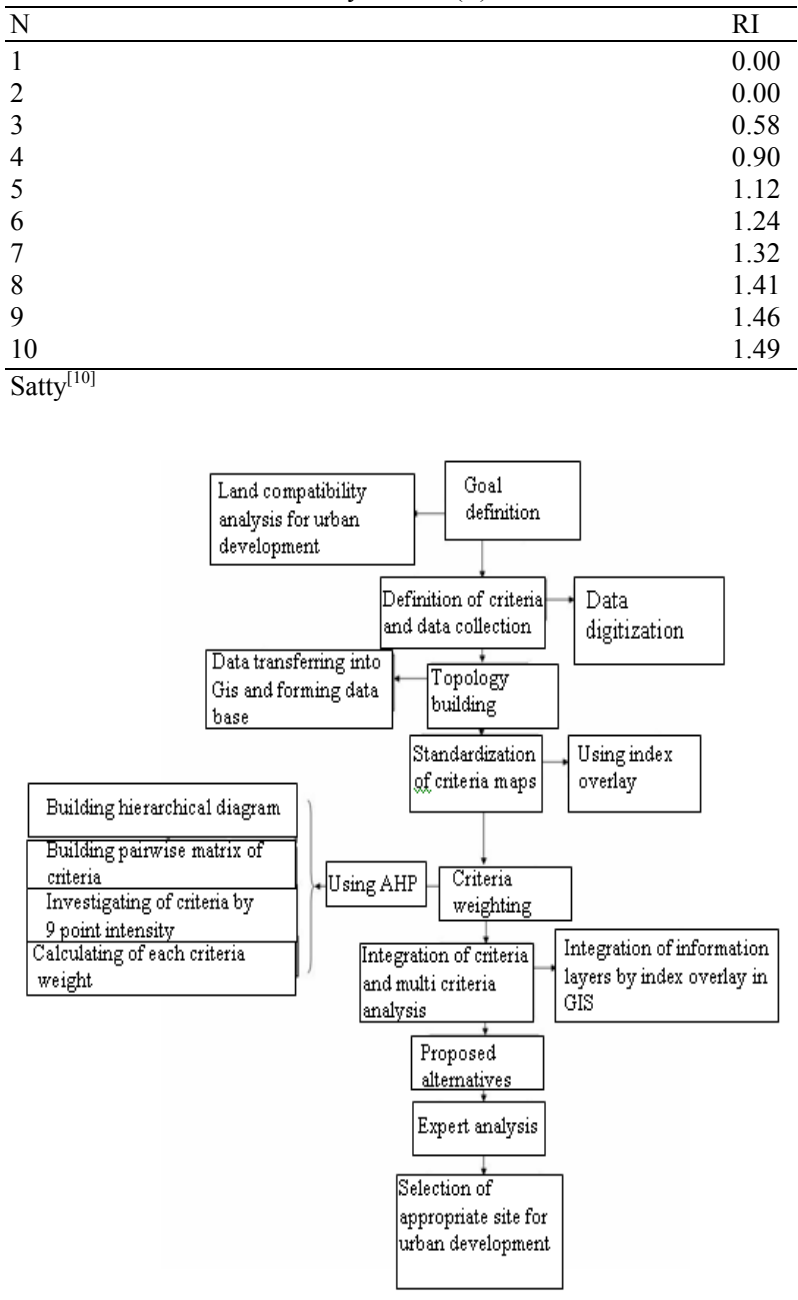

Fig. 1: The conceptual flow of the research

applicability is due to its simplicity, ease of use and great flexibility. It can be integrated with other techniques, for instance, mathematical programming in order to consider not only both qualitative and quantitative factors, but also some real-world resource limitations.

We have integrated this method with the Index Overlay method in the present study. In IO model the different factors and classes has different values and then a set of flexible maps will be provide which has a range of numbers. For example, gradient has different degrees for different purposes which may change from $3-10 \%$ or more. Here, an appropriate gradient for urban development is between $3-8 \%$. The process of weighting will be done for fault line, gradient direction, soil and alike. Then by two variable analyses the layers composite and each location with higher values would be selected. The conceptual flow of the research is illustrated in Fig. 1.

Selecting criteria of the land compatibility analysis for urban development: Physical planning for urban development should consider the geographical areas which are suitable for urban physical development in the regional and national level. The potential and the type of land use need different socio-economic and environmental studies ${ }^{[20]}$. Also many physical factors such as topography, gradient, soil and others should be investigated in the location where the possible urban development takes place there ${ }^{[21]}$. The present study has considered the following criteria to determine the appropriate land for urban physical expansion which are included: Land potential, distance to fault line, the dominant wind direction, topography and distance from the legal limit of the city, land limitations, distance from the main roads, distance from rivers and distance from urban infrastructure. Clearly, each criterion should be carefully examined and probably adjusted with respect to the local conditions.

The practice of the recommended process: The criteria will be weighted and the value of each it will be determined in the analysis process after selecting the most important influential criteria on the land compatibility analysis. The relative value of each criterion will be assigned by using AHP. The first step is the formation of hierarchical diagram and then the pairwise comparison will be done for measuring the importance of criteria. The 9-point intensity of relative importance scale of Saaty was used for such purpose. The pair wise comparison matrix has shown in Table 3.

The important point of this stage is the consistency ratio in comparisons. Researchers believe that in a scientific study, the amount of consistency ratio should be less or equal to 0.1 to be sure about our judgments. This figure has been 0.03 in this research which led to a high assurance of judgments. The relative weights of the criteria were determined by using mathematical methods such as mean. The weights of the given criteria have been obtained in the Table 4 .

Each criterion classified with respect to the aim and the value of each class is assigned in the process. The Index Overlay was used for weighting. 1 the different classes in this model and the existed elements were weighted, the result were series of flexible maps which include a range of numbers. For example distance from fault lines is classified and weighted in Table 
Am. J. Environ. Sci., 5 (1): 87-93, 2009

Table 3: The pairwise comparison matrix in AHP model

\begin{tabular}{|c|c|c|c|c|c|c|c|c|c|}
\hline & $\begin{array}{l}\text { Distance } \\
\text { from the } \\
\text { legal limits } \\
\text { of the city }\end{array}$ & $\begin{array}{l}\text { The dominant } \\
\text { wind } \\
\text { direction }\end{array}$ & $\begin{array}{l}\text { Land } \\
\text { potential }\end{array}$ & $\begin{array}{l}\text { Distance } \\
\text { from the } \\
\text { rivers }\end{array}$ & $\begin{array}{l}\text { Distance } \\
\text { to the } \\
\text { fault line }\end{array}$ & $\begin{array}{l}\text { Lands } \\
\text { limitations }\end{array}$ & $\begin{array}{l}\text { Distance } \\
\text { from the } \\
\text { infrastru- } \\
\text { ctures }\end{array}$ & $\begin{array}{l}\text { Distance } \\
\text { from the } \\
\text { main } \\
\text { roads }\end{array}$ & Topography \\
\hline $\begin{array}{l}\text { Distance from the } \\
\text { legal limits of the city }\end{array}$ & 1.00 & 0.33 & 0.20 & 4.00 & 0.25 & 2.00 & 5 & 3.00 & 0.50 \\
\hline $\begin{array}{l}\text { The dominant } \\
\text { wind direction }\end{array}$ & 3.00 & 1.00 & 0.33 & 6.00 & 0.50 & 4.00 & 7 & 5.00 & 2.00 \\
\hline Land potential & 5.00 & 3.00 & 1.00 & 8.00 & 2.00 & 6.00 & 9 & 7.00 & 4.00 \\
\hline Distance from the rivers & 0.25 & 0.16 & 0.12 & 1.00 & 0.14 & 0.33 & 2 & 0.50 & 0.20 \\
\hline Distance to the fault line & 4.00 & 2.00 & 0.50 & 7.00 & 1.00 & 5.00 & 8 & 6.00 & 3.00 \\
\hline Lands limitations & 0.50 & 0.25 & 0.16 & 3.00 & 0.20 & 1.00 & 4 & 2.00 & 0.33 \\
\hline $\begin{array}{l}\text { Distance from the } \\
\text { infrastructures }\end{array}$ & 0.20 & 0.14 & 0.11 & 0.50 & 0.12 & 0.25 & 1 & 0.33 & 0.16 \\
\hline $\begin{array}{l}\text { Distance from the } \\
\text { main roads }\end{array}$ & 0.33 & 0.20 & 0.14 & 2.00 & 0.16 & 0.50 & 3 & 1.00 & 0.25 \\
\hline Topography & 2.00 & 0.50 & 0.25 & 5.00 & 0.33 & 3.00 & 6 & 4.00 & 1.00 \\
\hline
\end{tabular}

Table 4: weighting of the given criteria

\begin{tabular}{ll}
\hline criteria & weight \\
\hline Land potential & 0.312 \\
Distance to fault line & 0.222 \\
Dominant wind direction & 0.155 \\
Topography & 0.108 \\
Distance from legal limit of the city & 0.074 \\
Land limitation & 0.051 \\
Distance from main roads & 0.035 \\
Distance from rivers & 0.025 \\
Distance from urban infrastructures & 0.018 \\
\hline
\end{tabular}

Table 5: Distance from the fault line

\begin{tabular}{ll}
\hline Weight & distance $(\mathrm{m})$ \\
\hline 1 & $0-300$ \\
3 & $300-600$ \\
5 & $600-1000$ \\
7 & $1000-2000$ \\
9 & $>2000$ \\
\hline
\end{tabular}

The layers would be overlapped on the base of their relative values by the help of Index Overlay in GIS. The sites with higher scores prioritized as first and second areas for the city future development. The most appropriate sites for urban development are shown in Fig.2.

\section{RESULTS}

The results of the present research could be listed as follow:

- The multi-criteria decision analysis can provide an appropriate framework for solution of the complicated issues of urban spatial planning when it is integrated to GIS. Such as urban land compatibility for urban development.

- The GIS based MCDA is very flexible and simple which many criteria could be analysis to solve a problem. How ever it needs to be mentioning that by increasing the numbers of criteria the process of

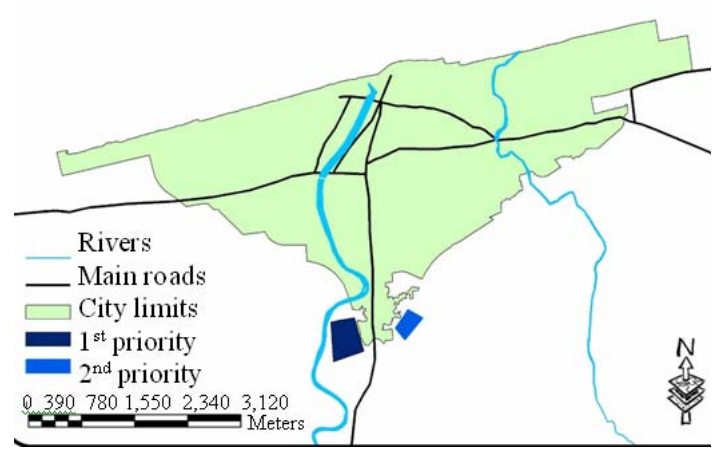

Fig.2: The most appropriate sites for urban development

weighting may counter with some difficulties, so the given criteria should consider the limitation of the model.

In the process of weighting the views of all interest groups could be asked with respect to their level of involvement. So this model can increase the public participation in the urban decision making. The future research can show the dimension of such opportunists.

- There are many criteria in land compatibility analysis for urban development which ignoring some of them can threat the urban sustainability. Also using a flexible and goal-oriented method could prevent some of the potential problems and decrease the cost.

- The recommended process for the city of Babolsar reveals that the most appropriated site for future development of the city is located in the southern parts (Fig.2). This case should be considered by the planners and especially the consulting engineers who design the city master plan. 


\section{DISCUSSION}

The main priority of national and local policy makers is to preserve the Northern strip on the country as Iran is a vast territory surrounded by mountainous ranges of Alborz and Zagros in the North and South west. The arid and semi arid of central parts provide less opportunities for agricultural development. The Southern Caspian Sea areas favor a moderate climate and a plain with highly fertile soil. As mentioned above, the area experienced a high urban growth which the expansion of urban infrastructures disappear the outskirt of the most of urban places. The only tool for urban growth control is master plans which lack proper power and logic to be realized completely. However, there has been some breakthrough to the monitor of urban expansion by using new methods during the recent years. But the new development mainly are used in the large cities especially the capital. It could be discussed that the study present a new way of selecting sites for the near future in the area which could be more appropriated.

\section{CONCLUSION}

Using the new models for urban land use planning is relatively new in Iran especially for the smaller cities. The multi criteria decision making provided a fresh ground to analysis a large number of factors which play important role in the location of different land uses. The GIS based model proved to be more efficient while has been quite economic compared to the traditional methods. Also the model could be generalized in the different areas of the country which have same problems.

\section{REFERENCES}

1. Etemad, G., 1998. Urban development and optimum land use. The Proceeding of Land and Urban Development Conference. The ministry of housing, March, Tehran, pp: 123-134.

2. Asgharpoor. M. J., 2006. The Multi-Criteria Decision Making. Tehran University Publication. Tehran. 4th Edn., pp: 220.

3. Higgs, G., 2006 . Integrating multi-criteria techniques with geographical information systems in waste facility location to enhance public participation. J. Waste Manag. Res., 24: 105-117. DOI: $10.1177 / 0734242 X 06063817$.

4. Li, D., M. Peng and Z. Shao, 2006. Design and Implementation of Urban Management and Service Grid Based on Spatial Database. In: ASIA GIS international conference, March 9-10, 2006, Johor, Malaysia, pp: 123-131.
5. Malczewski, J., 1999. GIS and Multicriteria Decision Analysis. 1st Edn., John Wiley, Toronto. pp: 392. ISBN 0471329444.

6. Eastman, J.R., A.K Kyem and J. Toledano, 1993. A procedure for multi-objective decision making in GIS under conditions of conflicting objectives. In: Proceedings of the 4th European Conference on Geographic Information Systems, March 29-April 1, Genoa, Italy, pp: 438-447.

7. Phua, M. and M. Minowa, 2005. A GIS-based multi-criteria decision making approach to forest conservation planning at a landscape scale: A case study in the Kinabalu Area, Sabah, Malaysia. J. Landscape Urban Plan., 71: 207-222. DOI: 10.1016/j.landurbplan.2004.03.004.

8. Ludin, A.N.M., A. Yaakup, S.Z. AbuBakar, A. Maidin and H. Ramle, 2006. GIS and Planning Support System for Klang Valley Region. In: ASIA GIS 2006, International Conference, Mar. 910, Johor, Malaysia, pp: 1-14

9. Carver, S. and S. Openshaw, 1992. A Geographic Information Systems Approach to Locating Nuclear Waste Disposal Sites. In: Waste Location: Spatial Aspects of Waste Management, Hazards and Disposal, Clark, M., D. Smith and A. Blowers, (Eds.). Routledge, London, pp: 105-127. ISBN 0415048249.

10. Satty, T.L., 1980. Analytic Hierarchy Process. 1st Edn., McGraw-Hill, New York. pp.320. http://www.ifm.eng.cam.ac.uk/dstools/choosing/ah p.html.

11. Lee, W.B., H. Lau, Z. Liu and S. Tam, 2001. A fuzzy analytical hierarchy process approach in modular product design. Expert Sys., 18: 32-42. DOI: $10.1111 / 1468-0394.00153$.

12. Yuksel, I. and M. Dagdeviren, 2007. Using the Analytic Network Process (ANP) in a SWOT analysis-A case study for a textile firm. J. info. Sci., 177 : 3364-3382. 10.1016/j.ins.2007.01.001.

13. Chen, C.F., 2006. Applying the Analytical Hierarchy Process (AHP) approach to convention site selection, J. Travel Res., 45: 167- 174. DOI: 10.1177/0047287506291593.

3. Chang, N.B. et al., 2007. Combining GIS with fuzzy multicriteria decision-making for landfill siting in a fast-growing urban region. J. Environ. Manag., $\quad 87$ : 139-153. 10.1016/j.jenvman.2007.01.011.

14. Kangas, J., 1992. Multiple-use planning of forest resources by using the analytic hierarchy process, Scandinavian. J. Forest Res., 7: 259-268. http://www.fao.org/agris/search/display.do?f=./199 2/v1814/SE9200290.xml;SE9200290. 
15. Harker, P.T. and L. Vargas, 1987. The theory of ratio scaled estimated: satty's analytical hierarchy process. Manag. Sci., 33: 1385-1403.

http://cat.inist.fr/?aModele=afficheN\&cpsidt=7655738.

16. Crouch, G. and J.R. Ritchie, 2005. Application of the analytic hierarchy process to tourism choice and decision making: a review and illustration applied to destination competitiveness. Tourism Analysis 10: 17-25.

DOI: $10.1177 / 0047287506291593$.

17. Muralidhar, K., R. Santhanam and R.L.Wilson, 1990. Using the analytic hierarchy process for information system project selection. Info. Manag., 18: 87-95. Doi: 10.1016/0378-7206(90)90055-M

18. Partovi, F.Y. 1992. Determining what to benchmark: An analytic hierarchy process approach. Int. J. Operat. Product. Manag., 14: 2539. DOI: $10.1108 / 01443579410062068$. http://www.emeraldinsight.com/Insight/viewConte ntItem.do;jsessionid $=$ C45DF850D61DAC6386680 $38 \mathrm{CEE7AE7EC}$ ? contentType $=$ Article\&hdAction $=1$ nkpdf\&contentId $=848792$.
19. Vaidya, O.S. and S. Kumar, 2006. Analytic hierarchy process: An overview of applications, Europ. J. Operat. Res., 169: 1-29. DOI:10.1016/j.ejor.2004.04.028.

20. Sedighiyan, I., 1993. Land investigation in physical planning. J. Abadiha, 10: 87-102.

21. Tofigh, F.,k 1993. Multi-criteria evaluation in physical planning. J. Abadiha, 11: 34-48. 